$$
\begin{gathered}
\text { 위치기반서비스를 활용한 안드로이드 퀴즈 } \\
\text { 애플리케이션 구현 } \\
\text { 현동림· 김종훈 } \\
\text { (제주대학교) }
\end{gathered}
$$

\title{
Development of the Educational Android Application using Location Based Service
}

\author{
Dong-Lim HYUN • Jong-Hoon $\mathrm{KIM}^{\dagger}$ \\ (Jeju National University)
}

\begin{abstract}
Smartphone and Tablet PC has become a popular. So, various location-based service applications are being made in the field of advertising, games, and search. However, the location-based services application is lacking in the field of education. Therefore, this study proposes a Location-based service application for Tablet PC, which can be take advantage in school. The application was designed with these considerations in mind. First, the application to increase the participation of the students take the form of play. Second, participating students are influencing each other. Third, through the promotion of the cycle has allowed long-term operations. This application will be used usefully in an environment that students use a individual Tablet PC through the spread of $\mathrm{e}$-textbooks.
\end{abstract}

Key words : Location based service, Game-based learning, Android

\section{I. 서 론}

디지털 컨버전스(Digital Convergence) 시대를 맞이하여 모바일 기기들이 종합 멀티미디어 기기 로 변모하고 있다. 특히 스마트폰 및 태블릿PC의 보급은 통신기능 이외에 엔터테인먼트, 비즈니스, 정보서비스 등 모바일 사용자들의 삶의 방식을 직접적으로 변화시키는 핵심 도구로 자리매김하 고 있으며, Smart-Life를 실현하기 위한 핵심 기 기로 거듭나고 있다. 이러한 사회의 변화는 교육 현장의 변화를 요구하고 있다. 미국 여러 대학교
와 고등학교의 아이폰 및 아이패드 보급 사례와 우리나라에서 진행되는 여러 전자교과서 시험학 교 운영사례를 볼 때 학교교육에 교육용 단말기 보급이 곧 이루어질 것으로 쉽게 예상 할 수 있 다. 또한 최근 몇 년간 모바일 기기들의 성능 향 상과 현실화 된 가격은 학교 교육에서의 모바일 기기 활용 가능성을 더욱 높여준다.

하지만 아직 학교 현장에서 활용할 수 있는 교 육용 애플리케이션의 수는 부족한 실정이다. 최 근 아이폰과 안드로이드폰의 경쟁에서 보듯이 풍 부한 애플리케이션의 뒷받침이 있을 때 모바일

† Corresponding author : 064-754-4913, jkim0858@jejunu.ac.kr

* 이 논문은 2011년도 제주대학교 학술연구지원사업에 의하여 연구되었음. 
기기의 활용을 극대화 할 수 있다.

이에 본 연구에서는 초등학생을 대상으로 학교 현장에서 활용 가능한 태블릿 PC용 교육용 애플 리케이션을 설계하고자 하며, 본 연구에서 설계 한 애플리케이션은 추가 연구를 통해 구현하고자 한다.

\section{II . 관련 연구}

본 연구에서 설계하고자하는 게임은 증강현실 을 통한 게임형식을 취하고 있으며 안드로이드 플랫폼을 통해 구현할 계획이다. 이에 이 장에서 는 게임기반 학습과 위치기반서비스, 안드로이드 에 대하여 알아보고자한다.

\section{1. 게임기반 학습(Game Based Learning)}

많은 연구들이 게임에 대한 부정적 영향과 긍 정적 영향에 대해 논쟁해왔다. 그러나 최근 들어 게임기반 학습에 관한 연구들은 대부분 긍정적 결과 산출에 더 많은 관심을 보이며, 상용 게임 을 교육적으로 활용하고자 하는 등의 점차 더욱 진보적인 움직임도 보여준다(위정현, 오나라, 2009)(Schrader, P. G., \& McCreery, M., 2008).

Prensky(2001)는 게임기반 학습이 필요한 이유 를 다음과 같이 설명한다(Prensky, M., 2001).

첫째, 게임 속에 학습 내용을 넣게 되면 몰입 (Engagement)을 가져올 수 있다.

둘째, 상호 작용하는 학습이 가능하므로 학습 목표에 따라 다양한 다른 형태로 학습을 할 수 있다.

셋째, 전체 상황 안에는 두 가지 또는 그 이상 의 해결방법을 함께 제공한다. 이것은 많은 해결 방법들 중에서 최선의 해결 방법을 문제 상황에 서 찾을 수 있도록 한다.

이러한 게임기반 학습은 집중력이 짧고 학습의 필요성을 느끼지 못하는 초등학생에게 매우 효과 적인 학습법으로서 초등학교 현장에서 주목을 받
으며 다양한 형식으로 활용되고 있다.

\section{2. 위치기반서비스(Location Based Service)}

위치기반서비스는 이동통신망이나 GPS 등을 통해 얻은 위치정보를 활용하여 이용자에게 여러 가지 서비스를 제공하는 시스템이나 서비스를 지 칭한다(최재호, 2008). 최근 GPS 수신 칩이 소형 화되고 가격이 하락하면서 다양한 기기에서 GPS 수신 칩이 장착되고 있으며 특히 스마트폰 및 태 블릿PC에서 GPS 수신 정보를 활용한 다양한 애 플리케이션이 개발되고 있다.

위치기반서비스를 제공하는 애플리케이션은 크 게 길안내와 같은 위치추적 서비스와 맛 집 찾기 와 같은 지역정보 제공 서비스로 나눌 수 있으 며, 특히 사용자에게 정보를 제공함에 있어 카메 라로 촬영한 실제 영상위에 사용자 위치정보를 활용한 정보를 겹쳐 제공하는 증강현실 기술은 사용자의 몰입감 및 정보 습득의 편리성을 높여 준다. IEEE연구 보고서에 따르면 게임과 위치기 반기술이 합쳐진 형태의 위치기반 모바일 게임은 제3세대 휴대폰 시장에서 가장 중요한 콘텐츠 역 할을 함과 동시에 주 수입원이 될 것으로 보고 있다(Benford, S., Anastasi et al. 2003).

\section{3. 안드로이드(Android)}

안드로이드는 구글이 주도하는 하드웨어, 소프 트웨어 업체의 공동 연합 OHA(Open Handset Alliance) 컨소시엄에서 개발된 플랫폼으로 개방 된 모바일 환경을 목적으로 하며, 다음과 같은 특징을 갖는다(Google, 2011).

첫째, 공개된 운영체제인 리눅스를 기반으로 한 운영체제 커널을 갖는다.

둘째, 자바 언어를 사용하고, 별도의 API를 추 가 제공한다.

셋째, 검증된 라이브러리들을 대거 포함하고 있다.

넷째, 개방된 환경으로 개발 툴과 관련 문서들 
이 무료로 제공된다.

안드로이드 플랫폼은 우리나라의 경우 애플사 에서 개발한 아이폰을 제외한 거의 모든 스마트 폰의 운영체제로 자리 잡았으며 아이패드를 제외 한 최근 공개되고 있는 최신 태블릿PC의 대부분 의 운영체제로 사용되고 있다(StatCounter Global Stats, 2011).

본 연구에서는 공개된 무료 플랫폼이라는 강점 과 다양한 단말 모델을 보유하고 있고, 또한 앞 으로도 다양한 업체에서 다양한 기종을 선보일 수 있다는 점에서 교육용 단말기 보급에 중요한 역할을 할 것으로 예상되어 안드로이드 플랫폼 기반 태블릿PC에서의 애플리케이션 개발을 목표 로 하였다.

\section{4. 교육용 애플리케이션 개발실태}

현재 학교현장에서 활용 가능한 교육용 애플리 케이션이 다양한 영역에서 개발되고 있다.

국어교과와 관련하여 개발된 애플리케이션의 예로는 육색사고모자 기법을 이용한 확산적 사고 토론학습모형 지원 애플리케이션(김은길, 김종훈, 2011)과 마인드맵을 이용한 사고정리 및 자료공 유 애플리케이션(현동림 외, 2011a)을 들 수 있다.

수학교과와 관련하여 개발된 애플리케이션의 예로는 단말기의 센서를 활용하여 면적을 구하는 애플리케이션(김은길 외, 2011a)과 쌓기모형을 입 체적으로 회전하며 관찰할 수 있는 애플리케이션 (김은길 외, 2011b)을 들 수 있다.

체육교과와 관련한 애플리케이션으로는 학생들 의 운동량 및 학교에서 사용하는 체격측정 방식 인 'PAPS시스템'을 지원해주는 애플리케이션(현 동림 외, 2011b)을 들 수 있다.

현장체험학습과 관련된 애플리케이션의 예로는 각 지역의 정보를 공유하여 유용한 현장체험학습 지를 찾을 수 있는 애플리케이션(김병수, 김종훈, 2011)과 교사가 지정한 장소의 정보를 전송받아 각 위치를 찾아갈 수 있게 해주는 네비게이션 기
능과 위치에 도착하였을 경우 관련 정보를 제공 해주는 애플리케이션(현동림, 김종훈, 2011)을 들 수 있다.

본 연구에서는 기존의 기존에 개발된 스마트폰 위주의 애플리케이션의 개발에서 벗어나 앞으로 학교 현장에서 보급되어질 것으로 기대되어지는 태블릿PC를 활용하여 애플리케이션을 개발하였 다. 또한 게임과 놀이를 접목함으로서 학생들에 게 새로운 교육적 경험을 제공해 줄 수 있을 것 으로 기대할 수 있다.

\section{III. 애플리케이션 설계}

본 연구에서 설계하고자 하는 애플리케이션은 초등학생들이 평소 많이 하는 잡기 놀이를 기반 으로 한 증강현실 게임으로, 태블릿PC의 휴대성 을 이용하여 학교 운동장을 놀이의 공간으로 활 용한다. 학생들은 운동장을 뛰어다니고 놀이를 즐기듯이 활동에 참여하며 퀴즈를 통해 학습한 다.

\section{1. 개발 목적}

본 연구는 초등학생을 대상으로 태블릿PC의 장점인 GPS와 센서를 이용한 위치정보와 공간의 제약을 벗어난 인터넷 접속 능력을 이용하여 학 교 운동장을 학생들이 자율적으로 참여하는 학습 의 장으로 만드는 것을 목적으로 한다.

\section{2 설계 방향}

애플리케이션은 '사낭'과 '대결'을 통한 '진화' 와 '퇴화'를 반복한다는 게임적인 요소를 갖는다. 설계의 방향은 학생이 운동장에서 태블릿 PC를 활용하여 증강현실 게임에 자율적으로 참여하고, 교사는 게임의 승패를 결정하는 퀴즈의 문제 은 행을 작성하여 학생들의 학습방향을 조절한다는 것이다.

애플리케이션의 활용 구조를 도식화한 그림은 
[그림 1]과 같다.

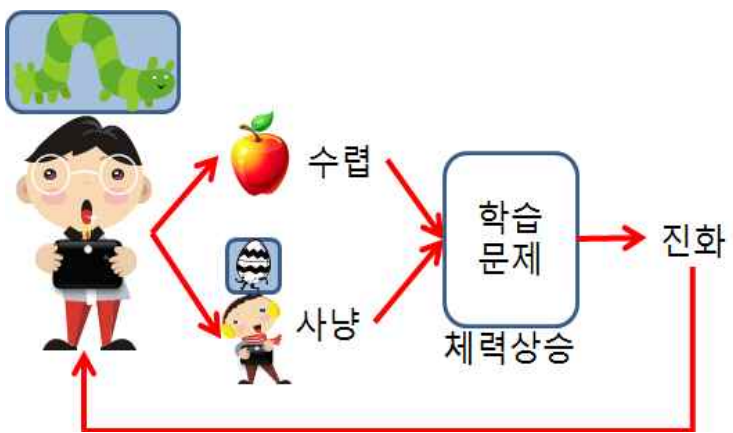

[그림 1] 애플리케이션 활용 구조

애플리케이션에 참여하는 캐릭터들은 시간의 흐름에 따라 '체력'이 자동으로 감소되며, '체력' 을 보충하기 위해서는 '수렵/사낭'을 해야 한다. ‘체력'이 $100 \%$ 를 넘으면 '진화’를 하며 $0 \%$ 가 되 면 '퇴화'한다. '진화’는 총 6단계인 '알, 애벌레, 개미, 거미, 조랑말, 여우, 사자' 순으로 진행되며 6단계에서 진화를 할 경우 개인 누적 점수가 올 라가고 1 단계로 돌아간다.

'수렴/대결' 모드에서 제공되는 퀴즈는 사전에 교사가 준비한 문제 은행에서 제시되며 애플리케 이션의 접속 날짜와 학습 진도를 고려하여 복습 또는 예습의 문제를 선정할 수 있다. 이 개인 누적 점수를 통해 개별 보상이 이루어지며 '진화' 가 사이클을 이루므로 애플리케이션의 장기적인 활용이 가능하다.

\section{3. 구조 및 화면 설계}

애플리케이션 동작에 필요한 데이터는 서버에 데이터베이스로 관리되며 사용자별로 테이블이 생성되어 개인 데이터가 저장된다. 개인별 저장 데이터 항목은 <표 $1>$ 과 같다.

교사가 애플리케이션 동작에 필요한 문제 은행 또한 데이터베이스로 관리되면 각 문항의 테이블 에 관리되는 데이터는 <표 2>와 같다.
〈표 1〉 사용자별 저장 데이터

\begin{tabular}{|c|c|}
\hline 구분 & 역할 \\
\hline ID & 사용자별 고유 식별 ID \\
\hline 레벨 & 현재 사용자의 레벨 \\
\hline 위치 정보 & $\mathrm{GPS}$ 값 \\
\hline 모드 & 현재 사용자의 모드 \\
\hline 누적 점수 & 현재 사용자의 개인 누적 점수 \\
\hline \multicolumn{2}{|c|}{ 〈표 2〉 문항별 입력 데이터 } \\
\hline 구분 & 역할 \\
\hline $\mathrm{ID}$ & 문항별 고유 식별 ID \\
\hline 교과 & 관련 교과 \\
\hline 단원 & 관련 단원 \\
\hline 차시 & 관련 차시 \\
\hline 난이도 & 문제의 난이도 \\
\hline 진도 & 관련 내용을 학습을 하는 시기 \\
\hline 유형 & 문항 유형(객관식, 단답식 등) \\
\hline 문항 & 화면에 출력되는 문제 \\
\hline 정답 & 문항의 정답 \\
\hline 정 답률 & 이 문항을 푼 학생들의 정답률 \\
\hline
\end{tabular}

애플리케이션은 [그림 2]와 같이 무선 인터넷 공유기를 통해 단말기와 서버의 통신으로 학생의 정보 및 퀴즈를 공유하는 구조를 이룬다.

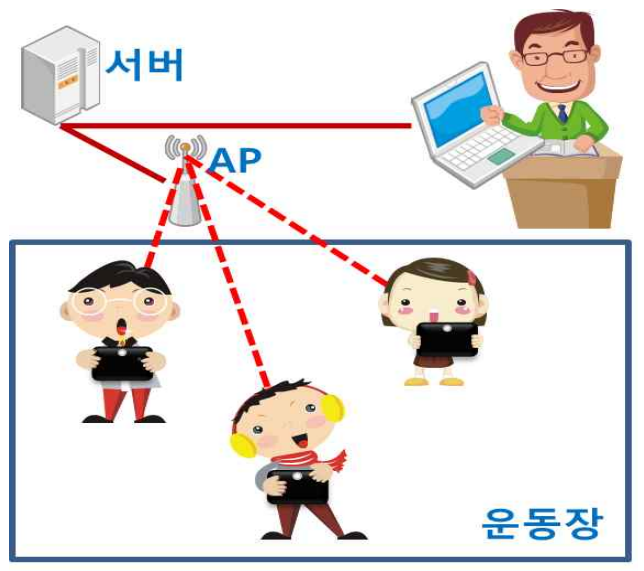

[그림 2] 동작 구조

각 태블릿PC는 각 사용자별 데이터를 서버에 서 0.5 초마다 전송을 받으며, 자신의 데이터가 수 정이 되었을 시에는 서버로 전송을 한다. 또한 
필요시 퀴즈 데이터를 서버에 요구하여 전송을 받을 수 있다. 교사는 문항별 정답률을 확인하여 학생들의 영역별 이해도 등을 파악할 수 있다.

애플리케이션의 화면은 역할을 구분하여 크게 3 부분으로 이루어지며 구성의 예는 [그림 3]과 같다.

화면은 크게 좌측의 증강현실 영역, 우측 상단 의 미니 맵 영역, 우측 하단의 모드 변경 버튼 영역으로 나뉜다.

증강현실 영역은 카메라에서 촬영된 화면에 접 속자들의 위치정보 및 레벨 정보를 전송받아 캐 릭터를 증강현실로 보여주며 현재 자신의 체력 및 현재 모드, 과녁이 표시된다.

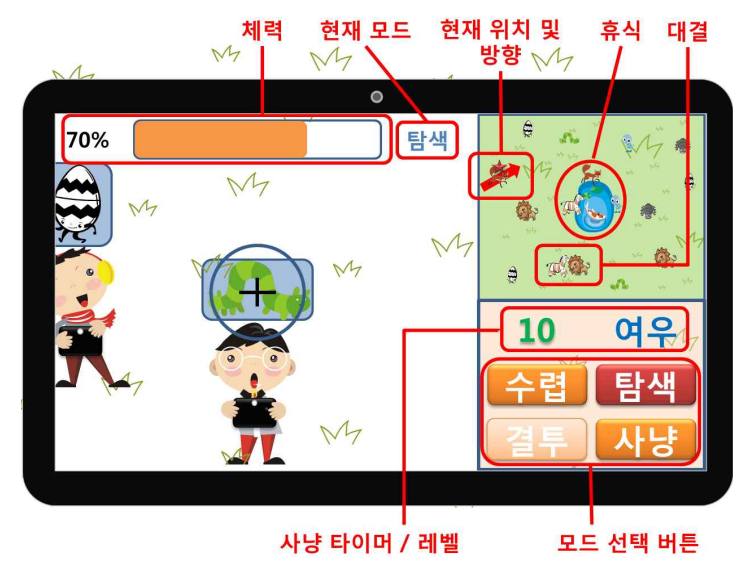

[그림 3] 화면 구성의 예

미니 맵 영역은 접속자의 위치정보 및 레벨을 바탕으로 접속자의 캐릭터를 위치에 따라 표시한 다. 또한 자신이 바라보는 시점도 화살표로 표시 해준다.

모드 변경 버튼 영역은 '수렵', '탐색', '결투', '사낭' 모드를 선택할 수 있으며, '결투'와 '사낭' 의 경우 해당 캐릭터를 과녁으로 겨낭할 때 활성 화 된다. 또한 '사낭' 모드 시 좌측상단의 타이머 가 작동되며 우측상단에는 현재 자신의 캐릭터가 표시된다.

\section{IV. 애플리케이션 구현}

애플리케이션은 학생들이 태블릿PC를 활용하 여 GPS 신호를 수신을 받을 수 있으며 인터넷을 사용할 수 있는 운동장과 같은 개방형 공간으로 일정넓이 이상으로 설정하였으며 환경은 <표 3> 과 같다.

〈표 3〉 학습 환경

\begin{tabular}{l|l}
\hline 구분 & 사양 \\
\hline \hline 공간 & ・가로 $50 \mathrm{~m} /$ 세로 $50 \mathrm{~m}$ \\
\hline $\begin{array}{l}\text { 무선 인터넷 } \\
\text { 공유기 }\end{array}$ & \begin{tabular}{l} 
・죄대향섭 속자 50 명 \\
\hline $\begin{array}{l}\text { 교육용 } \\
\text { 단말기 }\end{array}$
\end{tabular} \\
\hline
\end{tabular}

안드로이드 애플리케이션을 구현하는 데에는 특별히 고사향의 PC 및 서버를 요구하는 것은 아니며, 본 연구자가 활용한 제작환경은 <표 4> 와 같다. 본 제작환경은 개발용으로 제시한 것으 로 학교현장에서 활용할 시에는 동지 접속자를 고려하여 서버의 사향을 맞출 필요가 있을 것으 로 본다.

〈표 4> 제작 환경

\begin{tabular}{|c|c|c|}
\hline \multicolumn{2}{|c|}{ 구분 } & 사양 \\
\hline \multicolumn{2}{|c|}{$\begin{array}{l}\text { 구현 대상 } \\
\text { 운영체제 }\end{array}$} & - Android Honeycomb 3.1 \\
\hline \multicolumn{2}{|c|}{ 소프트웨어 } & $\begin{array}{l}\text { - Eclipse Helios } \\
\text { - Android SDK } 3.1 \\
\text { - Apache } 2.2 .14 \\
\text { - PHP 5.2.12 } \\
\text { - MySQL } 5.1 .39\end{array}$ \\
\hline \multirow{2}{*}{$\begin{array}{l}\text { 하 } \\
\text { 드 } \\
\text { 웨 } \\
\text { 어 }\end{array}$} & $\mathrm{PC}$ & $\begin{array}{l}\text { - CPU: Intel Core2 Duo E8300 } \\
\text { - Memory: 4GB } \\
\text { - OS: Windows } 7\end{array}$ \\
\hline & 서버 & $\begin{array}{l}\text { - CPU: Intel Xeon }(\mathrm{Tm}) 3 \mathrm{GHz} \\
\text { - Menory: } 1 \mathrm{~GB} \\
\text { - OS: Windows } 2008 \text { Enterprise }\end{array}$ \\
\hline \multicolumn{2}{|c|}{$\begin{array}{c}\text { 테스트 } \\
\text { 기기 }\end{array}$} & - Galaxy Tab 10.1 Wifi only \\
\hline
\end{tabular}




\section{1. 증강현실 구현}

본 연구에서 개발한 애플리케이션은 증강현실 을 사용한 게임을 제공함으로서 학생들이 태블릿 $\mathrm{PC}$ 를 사용하여 넓은 공간에서 활동을 유도하고 자 하였다. 따라서 화면 구성의 많은 부분을 증 강현실 영역으로 할당하였으며 구현한 실제는 [그림 4]와 같다.

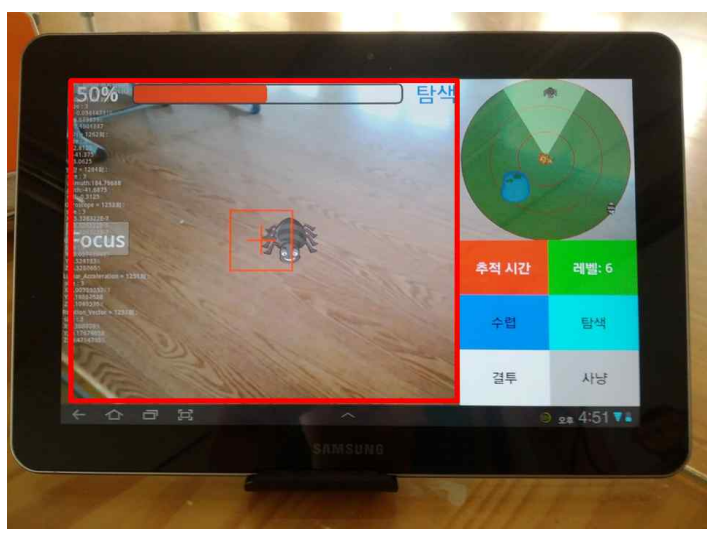

[그림 4] 증강현실 영역 구현

[그림 4]는 임의로 사용자들의 데이터를 입력 한 것으로 증강현실 영역에 다른 사용자의 레벨 에 맞는 캐릭터가 등장해 있다. 증강현실 영역의 중앙에 있는 ' + '표시 부분에 단말기를 조절하여 다른 사용자를 겨냥하게 되면 ' + '표시가 붉게 변 하고 사낭 모드와 같은 기능을 활용할 수 있다.

증강현실 영역의 상층부에는 사용자의 체력 및 현재 모드가 표시되며 왼쪽에 'Focus'버튼을 두어 사용자가 수동으로 초점을 맞추도록 하였다.

증강현실 영역의 데이터는 왼쪽 상단의 미니맵 데이터와 연동되어 표시된다.

\section{2. 사용자 위치 탐색 구현}

본 연구에서 개발한 애플리케이션을 사용자들 의 GPS 신호는 서버에 전송 하게 되고 그 정보 는 주기적으로 모든 사용자의 단말기에 전송된 다. 따라서 각 단말기에는 모든 사용자의 GPS
신호 정보가 주어지게 되어 모든 사용자의 위치 를 확인 할 수가 있다. 이러한 정보는 [그림 5]와 같이 애플리케이션의 오른쪽 상단에 위치한 미니 맵을 통해 확인이 가능하다.

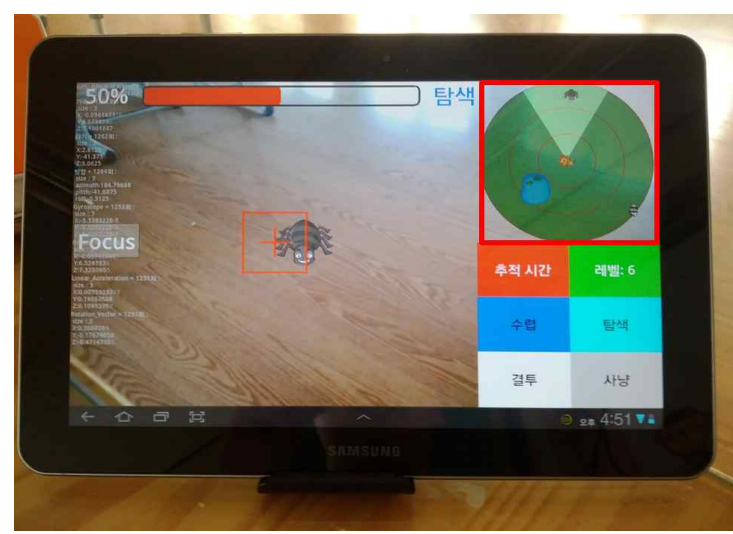

[그림 5] 미니맵 영역 구현

미니맵은 짙은 영역과 옅은 영역으로 이중구조 화 되어 있는데 짙은 영역은 단말기의 카메라가 안 비치는 곳이고 옅은 영역이 현재 단말기의 카 메라가 비치는 구역을 나타낸다. 미니맵의 정보 는 단말기의 센서정보(방위, 기울기) 및 단말기의 GPS신호 정보와 전송받은 다른 사용자의 GPS신 호 정보를 토대로 계산되어지며 주기적으로 업데 이트된다. 사용자들은 실시간으로 자신과 다른 사용자의 위치를 현재 자신의 위치 및 바라보는 방위에 맞게 파악할 수 있으며, 위치가 레벨에 맞는 캐릭터로 표현이 되어 애플리케이션을 활용 하는데 필요한 정보를 손쉽게 얻을 수 있다.

\section{3. 통신 구현}

각 단말기는 자신의 정보를 서버의 데이터베이 스에 전송하고, 수합된 정보를 수신 받게 된다. 또한 애플리케이션의 학습적 요소를 담당하는 학 습문제 또한 수신하고 문제를 푼 결과 또한 송신 하게 된다. 이런 과정은 통신료와 같은 문제를 해결해야하는 현실적인 어려움으로 $\mathrm{Wi}-\mathrm{Fi}$ 통신을 이용하게 구현하였다. 따라서 실제로 학교현장에 
서 활용하기 위해서는 운동장과 같은 일정 영역 에 'Wi-Fi Zone'을 구축해야 한다.

\section{V. 애플리케이션 활용}

본 연구에서 개발한 애플리케이션은 학생들이 학년 및 시간에 구애됨이 없이 놀이를 통하여 학 습을 하는 것을 전재로 구현을 하였으며 수업 시 간과 같이 시간을 정하여 활동 할 수도 있으며, 점심 시간과 쉬는 시간과 같이 일정한 시간을 정 하지 않고도 사용자 각자가 자유롭게 중간에 참 여 및 정지가 가능하여 그 활용도가 높을 것으로 기대한다.

<표 5>는 본 연구에서 개발한 애플리케이션을 활용하는 교사 및 학생의 역할의 예를 제시한 것 이다.

\section{〈표 5> 교사 및 학생의 역할}

\begin{tabular}{c|c|l}
\hline 구성원 & 활용 & \multicolumn{1}{|c}{ 역할 } \\
\hline \hline \multirow{5}{*}{ 교사 } & 학급 & $\begin{array}{l}\text { 학급 학생들에 게 제시할 학습 } \\
\text { 문제를 과목별 진도 및 난이도 } \\
\text { 를 고려하여 서버의 문항별 데 } \\
\text { 이터베이스에 등록 }\end{array}$ \\
\cline { 2 - 4 } & 학교 & $\begin{array}{l}\text { 학년에 맞는 문제를 난이도 및 } \\
\text { 문항 제시시기를 고려하여 문 } \\
\text { 항 데이터베이스에 등록 }\end{array}$ \\
\hline \multirow{5}{*}{ 학생 } & 학급 & $\begin{array}{l}\text { 수업 시간을 이용하여 학급 단 } \\
\text { 위로 애플리케이션을 실행하여 } \\
\text { 활용 }\end{array}$ \\
\cline { 2 - 4 } & 학교 & $\begin{array}{l}\text { 점심 시간 및 쉬는 시간을 이 } \\
\text { 용하여 전교생이 함께 활용 }\end{array}$ \\
\hline
\end{tabular}

\section{1. 기대 효과}

본 애플리케이션은 연구학교 및 파일럿 테스트 를 이용하여 기능 및 인터페이스를 개선할 계획 이며 본 애플리케이션을 활용한 학습의 기대 효 과는 다음과 같다.

첫째, 컴퓨터 게임 요소와 몸을 움직이는 놀이 요소를 모두 제시하고 있어 학생들의 참여 동기
가 클 것으로 예상한다.

둘째, 교사가 제시하는 학습 문제를 해결함으 로서 교사가 학생들을 계획적으로 학습시킬 수 있다.

셋째, 애플리케이션은 학생들이 최상위레벨에 서 진화를 하였을 경우 개인 보상 점수를 주고 다시 최하위레벨에서 실행되는 순환구조를 갖는 다. 따라서 교사는 개인 점수를 적절히 보상함으 로서 학생들이 애플리케이션을 장기적으로 활용 할 수 있도록 할 수 있다.

넷째, 게임을 통해 전략적 사고를 하고 신체를 활발히 움직임으로서 신체능력을 향상시킬 수 있 을 것으로 기대한다.

\section{VI. 결 론}

본 연구에서는 미래 학교교육 환경을 고려하여 태블릿PC를 활용한 교육용 애플리케이션을 설계 하였다. 초등학생의 인지발달을 고려하여 게임기 반 학습을 기반으로 위기기반서비스를 활용하였 기에 학생들은 태블릿 $\mathrm{PC}$ 의 휴대성을 통해 교실 을 벗어나 넓은 운동장을 활용할 수 있는 장점을 활용하여 마음 것 뛰어놀며 학습하게 될 것으로 기대한다.

하지만 아직 학교 현장에서 태블릿PC를 활용 한 수업을 하기에는 예산 및 기반 시설이 부족한 현실이다. 이에 교육용 저가의 태블릿 $\mathrm{PC}$ 의 보급 및 학교에서의 'Wi-Fi Zone'의 확대 등 교육 여 건이 개선되어야 할 것이다. 이러한 여건은 디지 털 교과서의 보급으로 향후 개선될 것으로 기대 하며, 본 연구에서 개발한 것과 같은 교육용 애 플리케이션이 교육 현장에서 활동될 수 있을 것 으로 기대한다.

본 연구에서 개발한 애플리케이션은 증강현실 과 GPS신호를 활용한 위치 탐색, 통신 기능을 이용하여 학생들이 컴퓨터 게임과 몸을 움직이는 놀이의 재미를 동시에 느끼며 학습할 수 있도록 
하였다. 이러한 유형의 애플리케이션은 장소의 다양성 및 퀴즈를 비롯한 미션의 다양화, ‘ $\mathrm{Wi}-\mathrm{Fi}$ Zone'의 확대가 이루어진다면 현장체험학습 등과 같이 다양한 학습 활동에 활용이 가능할 것으로 본다.

아이폰과 안드로이드폰의 경쟁에서 보듯이 콘 텐츠의 중요성은 날로 강조되지만 아직 학교 교 육현장에서 활용할 수 있는 교육용 애플리케이션 이 부족한 현실을 감안하여 앞으로 더욱 다양한 교육용 애플리케이션이 추가로 연구·개발되어 학 교 교육현장에 도움을 줄 수 있길 기대한다.

\section{참고 문헌}

김병수 · 김종훈(2011). 기하학 문제해결 능력 향 상을 위한 STEAM 교육 기반의 종이 접기 애 플리케이션의 설계 및 개발, 한국지식정보기술 학회 논문지 6(6), 103 110.

김은길 - 김종훈(2011). 확산적 사고력 함양을 위 한 안드로이드 기반 토론학습 시스템 개발, 컴 퓨터교육학회논문지 14(1), 137 146.

김은길 · 염미령 · 김종훈(2011a). 방향 센서를 활 용한 좌표 및 면적 측정 안드로이드 애플리케 이션 개발, 정보교육학회논문지 15(3), 439 447. 김은길 - 현동림 - 김종훈(2011b). 안드로이드 기반 입체도형 학습 콘텐츠 제작용 프레임워크의 설 계 및 구현, 정보교육학회논문지 15(1), 67 76.

위정현 - 오나라(2009). 온라인 게임을 활용한 전 략경영 교육의 효과 분석, 전략경영연구 $12(2)$, 139 149.

최재호(2008). 위치기반서비스(LBS) 산업동향과
시사점, 산은경제연구소.

현동림 · 김은길 · 김종훈(2011a). 안드로이드 기반 사고 공유 마인드맵 애플리케이션 구현, 수산 해양교육연구 23(2), 234 243.

현동림 - 김종훈(2011). 현장체험학습 지원을 위한 안드로이드 LBS 애플리케이션 개발, 정보교육 학회논문지 15(4), 579 587.

현동림 · 송경철 - 김은길 - 김종훈(2011b). 안드로 이드 기반 비만 관리 애플리케이션 개발 $\mathrm{BMI}$ 및 운동량 산출을 중심으로 -, 수산해양교 육연구 23(4), 568 581.

Benford, S., Anastasi, R., Flintham, M., Drozd, A., Crabtree, A., Greenhalgh, C., Tandavanitj, N., Adams, M. \& Row-Farr, J.(2003). Coping with uncertainty in a location-based game, IEEE Pervasive Computing, 2(3), 34 41.

Google(2011), What is Android?, http://developer. android.com/guide/basics/what-is-android.ht $\mathrm{ml}$.

Prensky, M.(2001). Digital game-based learning, New York, NY: McGraw-Hill.

Schrader, P. G., \& McCreery, M.(2008). The acquisition of skill and expertise in massively multiplayer online games, Educational Technology Research and Development, 56(6), 557 574.

StatCounter Global Stats(2011). Top 8 Mobile OSs in South Korea from Jul 10 to Jul 11, http://gs.statcounter.com/\#mobile_os-KR-mon thly-201007-201107.

- 논문접수일 : 2012년 05월 08일

- 심사완료일 : 1차 - 2012년 05월 27일

- 게재확정일 : 2012년 06월 03일 